\title{
A rapid and precise method for determining water content in nuts as a tool for determining their quality during storage
}

\author{
Małgorzata Kowalska $^{1}$ (1) Sławomir Janas $^{2} \cdot$ Paulina Mitrosz $^{1}$
}

Received: 5 July 2021 / Revised: 14 October 2021 / Accepted: 8 November 2021 / Published online: 16 February 2022

(C) The Author(s) 2022

\begin{abstract}
This study was designed to examine impact of storage conditions on hazelnut quality and to develop a quick method for testing hazelnut moisture. The change of sample mass and water content were assessed by convection drying method and by means of a moisture analyzerIR radiation. The samples were tested as: nuts, nut kernels, crumbled nut kernels, husk of nuts. They were stored in closed and open packages at $45 \%$ and $80 \%$ humidity and at constant temperature $\left(23{ }^{\circ} \mathrm{C}\right)$. It has been observed that at the humidity of $45 \%$, the hermetic packaging reduced hazelnut mass loss by $18 \%$, and the hazelnut husk caused reduction of mass loss of the kernel by $5.5 \%$. It was found that the best storage effects were obtained at a relative air humidity of $80 \%$ (i.e. change in hazelnut weight $2.18 \%$, kernels $0.78 \%$, shell 1.4\%). At this moisture content, in comparison with the moisture content equal to $45 \%$, a lower loss of hazelnut weight by $4.65 \%$, kernel weight by $10.79 \%$, shell weight by more than two times was found when the samples were stored without packaging. Water desorption from hazelnut stored under these conditions was reduced to $0.4 \%$ for packaged kernels and to $3 \%$ for unpackaged product. Determining the water content by the IR radiation method, compared to the standard method, took much less time, it took about 1 h. 5 min (approx. 6 times faster) with a measurement accuracy of $0.26 \%$.
\end{abstract}

Małgorzata Kowalska

mkowalska7@vp.pl

1 Department of Management and Product Quality, Faculty of Chemical Engineering and Commodity Science, Kazimierz Pulaski University of Technology and Humanities, Radom, Poland

2 Radwag Balances and Scales Company, Toruńska Street 5, 26-600 Radom, Poland
Therefore this paper proves that the described method positively influences time restrictions especially when the duration of water content analysis is a key determinant. According to the authors, it can be implemented in both laboratory and industrial tests, saving time and acting immediately when the technological process requires support.

Keywords Quality of hazelnuts · Water content . Packaging $\cdot$ Environmental conditions

JEL Classification L66 · Q18

\section{Introduction}

Water is an ingredient that has a significant influence on the quality of food products (Adegbola et al. 2019; Kaya et al. 2011). It is an integral part of the structure of each food product, however sometimes an excess of water in a product is undesirable, because it can lead to hydrolytic or oxidative changes in the product. As a result of these transformations, the physicochemical properties of the product change, which in turn may lead to a decrease in product quality. Information on real water content value is required at the stage of production, during an inter-operational control and in the course of final product assessment. Either lack of such information, or incorrect method testing water content in a product, may result with lower finished product quality, unintentionally short shelf-life of the product, and production loss. This concerns each product, also hazelnuts, which due to their pro-health properties are an important element of human feed chain. The main problems are mould infections, mycotoxin contaminations, 
(Campbell et al. 2003; Navaro 2006), and too excessive amount of water in product.

The quality is normally satisfactory if a product contains a moderate amount of water. The range of tolerance for water content is key to product processing and final evaluation. Freshly harvested hazelnuts contain plenty of free water (about 20\%), which induces molding and enzymatic action. The degradation process of nuts is accelerated by, among other things, too high humidity. This leads to degradation of lipids and vitamins (Savagea et al. 1997; Derewiaka et al. 2014). Therefore, harvested nuts must be dried (humidity about 5\%) to improve their stability (San Martin et al. 2001). Ghirardello et al. (2013) state dried ripe hazelnuts can be stored for even 2 years, though their life depends on conditions of the storage. It should be noted the changes during storage affect not only husks (changing dimensions, hardness, cracking), but also kernels, e.g. lipid oxidation processes, sensory changes, changes of appearance or nutritional value (Ghirardello et al. 2013; Guiné et al. 2015; Moscetti et al. 2012). Temperature and humidity are well-known, important parameters at the time of storage (Savage et al. 1997; Tavakoli et al. 2019). A greater storage humidity is related to water activity in nuts, which in turn leads to moulding, colour changes, rancidification, and degradation of vitamin E. Application of low temperatures restricts these processes and helps to maintain good quality of nuts over a long time. Adverse changes in their structure are limited by application of modified storage atmospheres in respect of $\mathrm{N} 2$ and/or CO2 (Markuszewski and Kopytkowski 2015).

With the above problems in mind, the authors made an attempt to analyse change in hazelnut weight and water content depending on storage method and packaging type, the size of hazelnut crumble level was referred to.

For this purpose, a proprietary method of water content determination in hazelnut was adopted, which method is realised using a moisture analyzer. Increase of the temperature inside the drying chamber is a consequence of convection air flow and infrared radiation. Knowledge of most researchers on how to dry samples comes from study of standard regulations describing a method of convection drying in the temperature of $105^{\circ} \mathrm{C}$ within about $3 \mathrm{~h}$. It is impossible to apply the parameters of a standard-provided method in a moisture analyser, the reason for that is a different way of supplying the heat to a product. Therefore this research aimed also to determine optimal parameters of the drying process performed using the moisture analyzer, which parameters would allow to obtain a result comparable to the result provided using standard-specified method, however, in much shorter time. This was a secondary aim resulting from operational goals of the conducted research. The presented method seems to be uncomplicated and indeed it is, the key component when designing a right procedure for water content determination is validation of the method for a particular food product. Unfortunately, those methods that are adopted for water content determination, particularly in research laboratories and in industry refer to general manufacturer recommendations, no validation is performed. This paper presents possibility of use of validated method intended for a particular product, in other words it shows how to monitor product quality both fast and precisely.

\section{Experimental part}

\subsection{Material}

The test was carried out on Halle hazelnuts, purchased in retail. $1 \mathrm{~kg}$ of randomly selected hazelnuts was dispensed from a large pile of the product. Prior the test, the hazelnuts were preconditioned in laboratory ambient conditions, in temperature of $23{ }^{\circ} \mathrm{C}$ and relative humidity of $45 \%$, for 5-day long period of time. In the course of the tests the samples were stored in $20 \mathrm{~cm}^{3}$ containers, made of seethrough polystyrene (PS). Some of the containers featured aluminium lid, this allowed to provide isolated space within which the samples were stored.

\subsection{Methods}

The purpose of the biometric research of hazelnuts was to determine the quality of hazelnuts, husks and kernels in accordance with the European Commission Regulation (2002). This was necessary to conduct further studies related to changes in weight and water content. No features disqualifying the sample were noted. The biometrics concerned the variability of the geometrical dimensions of the shelled nuts as shown in Fig. 1. Hazelnut axial measurements such as length (L), width (W) and thickness (T) were

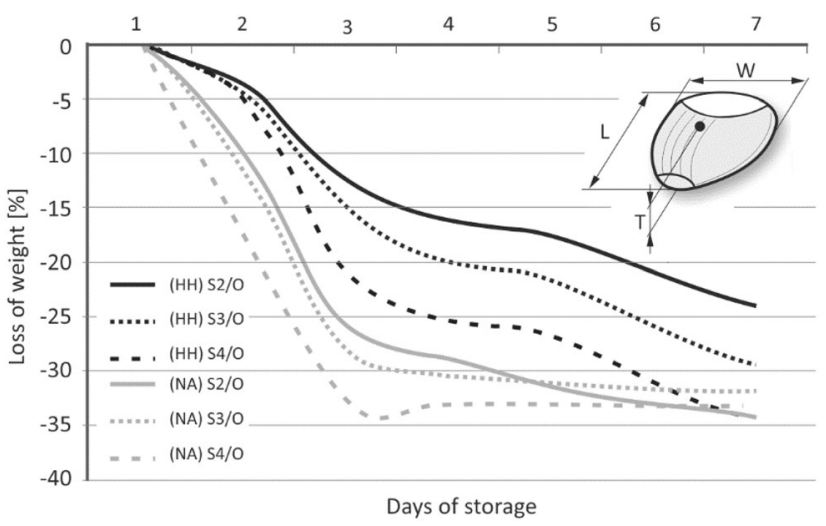

Fig. 1 Change in weight of hazelnuts stored in (NA) and (HH) conditions, depending on size of crumble level 
made with a digital calliper with a reading accuracy of $0.01 \mathrm{~mm}$. The control sample consisted of 30 randomly selected hazelnuts. The tests were carried out in constant ambient conditions, for the measurement of temperature and humidity, the Kestrel 4000 anemometer by NielsenKellerman. The temperature was measured with a resolution of $0.1{ }^{\circ} \mathrm{C}$ and measurement uncertainty of $\pm 1{ }^{\circ} \mathrm{C}$, relative humidity with a resolution of $0.1 \%$, measurement uncertainty of $\pm 3 \%$.

The water content is an important parameter determining the quality of hazelnuts. Unfortunately, the normative method requires more than $6 \mathrm{~h}$ of drying, which does not allow for quick periodic determination whether the storage conditions are optimal. It was therefore reasonable to verify the suitability of a faster method based on IR radiation (moisture analyzer), which can be applied in water content testing. The important parameters of the moisture analyzer method are the drying temperature and the termination criterion. Heat is delivered to the sample by convection, conduction and infrared radiation. Both convection and conduction require a medium for heat transfer. Conduction is the transfer of heat deep into the sample, which can be an important factor when the thickness of the nut sample is significant. Convective heat transfer is the interaction of warm air molecules with the surface layer of the sample under analysis. In this case, the top layer of the dried sample may have a significantly different temperature from its deeper layers, and the heat transfer process is critical to the time and accuracy of the analysis being conducted. Infrared radiation is an electromagnetic wave that does not require a heat transfer medium. Heat transfer occurs when emitted radiation strikes another body and is absorbed. To determine the water content, it is sufficient to determine the weight of a wet sample and the weight of a dry sample after the water has been removed from the sample structure. Weighing a wet sample is usually done in a static state, while the mass of a dry sample is determined in a dynamic state, when the drying chamber is at a high temperature, e.g. $105{ }^{\circ} \mathrm{C}$. For this reason, the dry mass of a sample is defined not as a single measurement, but as the invariability of its mass in the range of $1 \mathrm{mg}$ during a fixed time, e.g. $60 \mathrm{~s}$. Observing the mass of the sample during this time allows one to be sure that its mass is stable, so the desorption of water is completed. By changing the drying temperature and the criterion describing the state of the dry sample, the drying method can be optimized to match specific features of the analyzed sample such as color, density, structure, type of water built up in the structure.

A MA.R series moisture analyzer produced by Radwag Wagi Elektroniczne, Poland, was used in the study. Drying temperature was regulated with $1{ }^{\circ} \mathrm{C}$ precision. The water content was calculated using the following equation. $w c=100 \% \cdot\left(m_{1}-m_{2}\right) / m_{1}$

where wc-product water content, $\mathrm{m}_{1}$-mass of a product containing water, $\mathrm{m}_{2}$-mass of a dehydrated product.

Complete dehydration of a product guaranteed stability of the product mass within $1 \mathrm{mg}$ range observed for at least $25 \mathrm{~s}$. Water content test was carried out for the hazelnuts after 30-day long conditioning in stable laboratory environment, temperature $23{ }^{\circ} \mathrm{C}$, humidity $45 \%$. From a laboratory sample, a test sample was extracted. The kernels were separated from the husks, then they were crumbled into pieces not greater than $2 \mathrm{~mm}$, next the pieces were stirred in order to form a homogenous sample. From thus prepared material, unit samples of 5-6 g mass were selected. The measurement was carried out in a temperature of $100{ }^{\circ} \mathrm{C}$. Optional water content determination was carried out following standard-provided method in accordance with recommendations of European Commission (2002).

Mass variation test was carried out in simulated 9-day long period of validity. The test consisted in recurring control of mass of hazelnut stored in humidity of $45 \% \pm 5 \%(\mathrm{NA})$ and $80 \% \pm 5 \%(\mathrm{HH})$. During the test, stable temperature of $23{ }^{\circ} \mathrm{C} \pm 0.5{ }^{\circ} \mathrm{C}$ was maintained for each environment. Mass measurement was performed using MA 50.R moisture analyzer manufactured by Radwag Wagi Elektroniczne, Poland. Readability was $1 \mathrm{mg}$. Prior to each measurement series the moisture analyzer was adjusted with an external $50 \mathrm{~g}$ mass standard of class E2. Analytical samples of the hazelnut for mass variation test was marked in accordance with the below specification:

- Nuts in husks stored in an open packaging $\rightarrow(\mathrm{S} 1 / \mathrm{O})$

- Nuts in husks stored in a closed packaging $\rightarrow(\mathrm{S} 1 / \mathrm{C})$

- Nuts without husks stored in an open packaging $\rightarrow(\mathrm{S} 2 /$ O)

- Nuts without husks stored in a closed packaging $\rightarrow(\mathrm{S} 2 / \mathrm{C})$

- Crumbled nuts, i.e. ca. 3-mm thick slices, stored in an open packaging $\rightarrow(\mathrm{S} 3 / \mathrm{O})$

- Ground nuts stored in an open packaging $\rightarrow(\mathrm{S} 4 / \mathrm{O})$

- Husks stored in an open packaging $\rightarrow(\mathrm{S} 5 / \mathrm{O})$

- Husks stored in a closed packaging $\rightarrow(\mathrm{S} 5 / \mathrm{C})$

The course of the experiment is shown graphically in Fig. 2. Thus prepared samples were placed in containers (PS), their initial gross weight was determined. In the course of tests, change in weight of an empty reference container, placed in an environment of higher humidity, was determined. Empty container weight determination was done with the aim of taking into account the value of deviation being a result of potential increase of plastic container weight, when calculating change in weight of 
Fig. 2 The methodology for changes in nut weight and moisture content

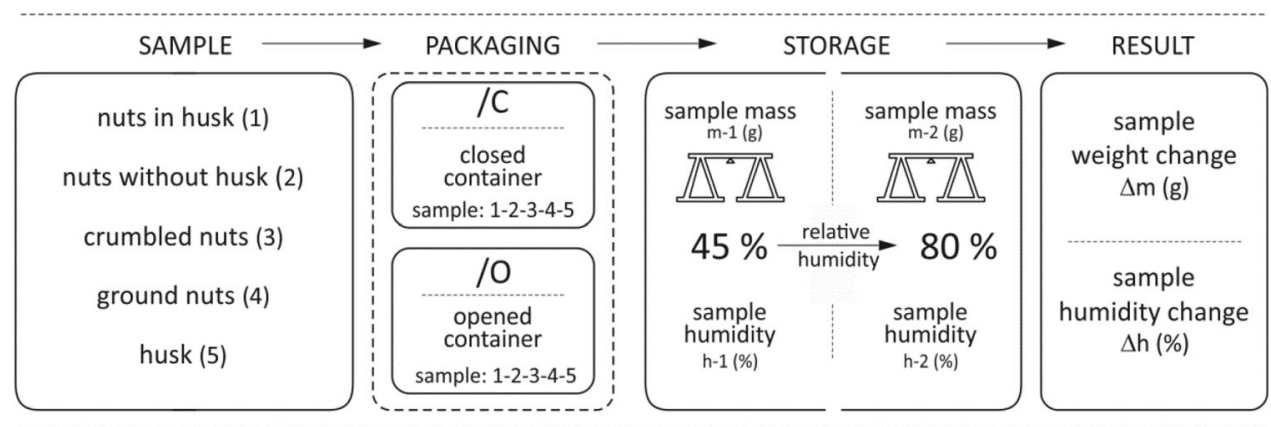

analysed samples. Mass of analysed samples was calculated using the following equation.

$m_{R E F(i)}=m_{G(i)}-m_{P(i)}$

where $m_{R E F(i)}$ - reference net weight of analysed sample, $\mathrm{m}_{\mathrm{G}(\mathrm{i})}$ - gross weight of analysed sample,

$m$ P(i) - mass of an empty container used to store samples.

The change in the weight of nuts is the result of sorption processes, desorption of moisture by the analyzed sample and potential changes in the weight of the container in which the samples were stored. When the mass of the container is constant during the test, the equation for determining the mass change of the analyzed samples is as follows:

$m_{R E F(i)}=m_{G(i)}$

Assessment of environmental conditions influence on change in samples weight, was done on the basis of difference between current weight value, recorded on the day of the measurement, and the initial weight value; the difference was calculated using the below equation.

$m_{D n(i)}=m_{i(n)}-m_{R E F(i)}$

where $m_{\text {Dn(i) }}$ - analysed sample weight difference in $n^{\text {th }}$ test interval, $\mathrm{m}_{\mathrm{i}(\mathrm{n})}-$ analysed sample weight in $\mathrm{n}^{\text {th }}$ test interval, $\mathrm{m}_{\mathrm{REF}(\mathrm{i})}$ - reference weight of analysed sample, recorded at the beginning of the test.

\subsection{Statistical analysis}

When it comes to statistical analysis of water content determination in hazelnuts, Q-Dixon test was carried out in order to check whether there were no results affected by serious error. For significance level of $95 \%$ and 10 degrees of freedom it was checked whether $\mathrm{Q}_{1}$ and $\mathrm{Q}_{\mathrm{n}}$ values were not greater than the critical value.

$Q_{1}=\frac{x_{2}-x_{1}}{R}<Q_{k r}$

value.
$Q_{n}=\frac{x_{n}-x_{n-1}}{R}<Q_{k r}$

where $\mathrm{R}$ - range in measurements series calculated as difference between maximum and minimum value, $\mathrm{x}-$ successive measurements in the series, $\mathrm{Q}_{\mathrm{kr}}$ - tabular value conditioned by the number of degrees of freedom and significance level.

\section{Results and discussion}

Average biometric measurements of the nuts were: length $2.14 \pm 0.14 \mathrm{~cm}, \quad$ width $\quad 1.97 \pm 0.10 \mathrm{~cm}, \quad$ height $1.93 \pm 0,11 \mathrm{~cm}$. The tested parameters varied from 2.62 to $1.87 \mathrm{~cm}$ for length, $1.82 \mathrm{~cm}$ to $2.23 \mathrm{~cm}$ for width, and 1.74 to $2.11 \mathrm{~cm}$ for height. Similar variations of biometric results were found by (Ercisli et al. 2011), who examined properties of nuts of 12 hazel genotypes.

Husk nut weight averaged $8.16 \pm 0.51 \mathrm{~g}$, with values measured fluctuating from 8.92 to $7.22 \mathrm{~g}$, while kernel weight averaged $6.04 \pm 0.47 \mathrm{~g}$, varying between 5.46 and $6.93 \mathrm{~g}$. Precise determination of nut dimensions and weight may come useful in production separation processes, while legally it is a factor in their classification under the Commission Regulation (EC) No. 1284 (2002). On the other hand, nut size influences consumers' evaluations via its emotional quality. This is important to marketing strategies.

In the course of the experiment nuts in husks and nuts without husks, both crumbled and not crumbled were analysed. During analytical samples preparation, it was determined that $49.7 \%$ of the total hazelnut weight value was hazelnut kernel. The above value is a bit higher than the value obtained by Ciemieniewska and Ratusz (2012), who during her tests, which were performed after 6-month long storing period, examined kernels of the following hazelnuts types: Catalan ( $43.41 \%$ of total hazelnut weight), Webba Cenny (45.18\% of total hazelnut weight) and Cosford (46.44\% of total hazelnut weight). The obtained percent value, regarding the kernel, is higher due to a different test methodology adopted. In comparison to 
Ciemieniewska and Ratusz (2012), the conditioning did not take as long, the nuts were conditioned for a much shorter period of time.

Before examining the changes in the weight of nuts as a result of their storage in changing environmental conditions, the water content in shell, nuts kernels and crumbled nut kernels was determined. The water content in the husk was $22.01 \%$. In the case of the nut kernels the value obtained was $34.05 \%$. The values are comparable with the results obtained by Markuszewski and Kopytkowski (2015) for the Catalan hazelnut $(34.6 \%$ water content) and the Giant Hall (34.5\% water content), stored for 3 months at 85-95\% humidity and temperature of approx. $1{ }^{\circ} \mathrm{C}$ in a normal atmosphere. The initial water content that was determined was the reference for determining how the storage conditions of the nuts affect the sorption and desorption of moisture.

During the tests, loss of analysed samples weight was observed regardless of storage ambient conditions. Figure 1 presents change in weight of hazelnuts without husks, stored in (NA) conditions and in ( $\mathrm{HH})$ conditions, depending on size of crumble level.

It was observed that change in weight of hazelnuts stored in (NA) is more dynamic than in case of sample stored in $(\mathrm{HH})$ conditions. This was observed for all types of the tested samples. It was noted that in the last stage of the test, weight loss for $\mathrm{S} 3 / \mathrm{O}$ and $\mathrm{S} 4 / \mathrm{O}$ samples was comparable, $31.83 \%$ and $33.15 \%$. On the basis of slope of the curves presenting weight loss of $\mathrm{S} 2 / \mathrm{O}$ samples, stored in (NA)-(HH) conditions, it can be concluded that when it comes to total change in weight, the obtained values will be comparable. This however requires the test to take much more time.

The slightest loss of weight was recorded for $\mathrm{S} 2 / \mathrm{O}$ sample stored in $(\mathrm{HH})$ conditions. This value leads to a conclusion that the best storage-related results are guaranteed for the environment of higher humidity, ca. 80-85\%. Similar conclusions were drawn by Markuszewski and Kopytkowski (2015), who stated that in the course of 7-day long durability test, carried out in temperature of $21-23{ }^{\circ} \mathrm{C}$ and humidity of $40-60 \%$, the value of dry mass content in hazelnut increased more than during 2-3 months of conditioning in a cold store, in $0-1{ }^{\circ} \mathrm{C}$ temperature range and $85-90 \%$ humidity range.

In case of $\mathrm{S} 2 / \mathrm{O}$ sample stored in $\mathrm{HH}$ ) conditions, the loss of weight was more than $10 \%$ lower than in case of the same sample stored in (NA) conditions. For sliced sample $(\mathrm{S} 3 / \mathrm{O})$ the loss of weight, given in percent, regardless of the environment was about $30 \%$. In case of $(\mathrm{HH})$ conditions the value was ca. $2.44 \%$ lower. It was observed that mass of sample, stored in (NA) conditions, and subjected to grinding ( $4 / \mathrm{O}$ sample), changed by $33.69 \%$. It is not possible to compare change in weight value of such sample stored in $(\mathrm{HH})$ conditions, this is due to the fact that after 3 days the sample got covered with mould. The mould made it difficult to assess correctly change in the sample weight. Similar process, however on a smaller scale, was observed for $\mathrm{S} 3 / \mathrm{O}$ sample stored in $(\mathrm{HH})$ conditions. No mould formed on $\mathrm{S} 2 / \mathrm{O}$ sample stored in the same environment. It can be stated that hazelnuts without husks that are not processed mechanically by grinding, feature layer protecting them against impact exerted by the environment. Similar conclusions were drawn by Chlebowska-Śmigiel and Gniewosz (2009), who performed test assessing hazelnuts quality. They noted that in case of hazelnuts, stored for 2-3 months, rate of saponification of fats, expressed by acid number ( $\mathrm{LK}$ value of $0.06 \mathrm{mg} \mathrm{KOH} / \mathrm{g}$ ), and fat oxidation number, expressed by peroxide number (LOO_value of $0.07 \mathrm{mmola} \mathrm{O}_{2} / \mathrm{kg}$ ) both increased significantly in relation to the initial values at the test start. According to them, the low initial values, LK and LOO, are caused by the fact that the hazelnut features a brown layer, protecting it against unfavourable influence of ambient conditions.

The greatest loss of weight, expressed in percent, was observed for samples stored in (NA) conditions. The loss, much greater when compared to loss of weight of sample stored in $(\mathrm{HH})$ conditions, was a result of too low humidity. In the course of analysis of samples stored in (NA) conditions, dynamic process of water release was noted. Such process is caused by sensory and quality-related changes of the hazelnuts, (Papetti and Carelli 2013). Loss of weight of $\mathrm{S} 2 / \mathrm{O}, \mathrm{S} 3 / \mathrm{O}, \mathrm{S} 4 / \mathrm{O}$ samples, expressed in percent, and related to the initial values for both (NA) and $(\mathrm{HH})$ conditions, is presented in Table 1.

During the tests, the amount of water desorption from samples S1 and S2 was assessed in relation to their storage and environmental conditions.

For this reason two samples were selected and placed in (NA) and (HH) conditions in an open (O) and closed (C) container. The results obtained during the test are presented in Fig. 3 and Table 2.

The greatest loss of weight, and dynamics of change, was recorded for S1/O sample stored in (NA) conditions $(21.97 \%)$ (Table 2). During the first stage of the test, the weight value decreased by ca. $19 \%$, within the following 4 days it decreased only by $4 \%$. Change in weight of S1/O sample, noted during the second stage was less dynamic, stabilisation of the sample weight was observed. For S1/C sample (closed), the obtained weight value was lower only by $3.91 \%$, i.e. more than 5 times than in case of $\mathrm{S} 1 / \mathrm{O}$ sample (open). Even though the sample was protected against influence of ambient conditions, constant dynamics of changes in weight was observed.

For S2/C sample (nut without the husk) change in weight of $9.4 \%$ was recorded, this value was twice greater 
Table 1 Loss of weight of hazelnuts, expressed in percent, presented in relation to initial weight value, and with regard to ambient conditions and size of crumble level

\begin{tabular}{llll}
\hline Sample type & S2/O (\%) & S3/O (\%) & S4/O (\%) \\
\hline$\Delta \mathrm{m}_{(\mathrm{HH})}$ & 23.33 & 29.31 & 33.96 \\
$\Delta \mathrm{m}_{(\mathrm{NA})}$ & 34.12 & 31.75 & 33.24 \\
Difference of samples' weight change $\Delta \mathrm{m}_{(\mathrm{NA})}-\Delta \mathrm{m}_{(\mathrm{HH})}$ & 10.79 & 2.44 & -0.72 \\
\hline
\end{tabular}

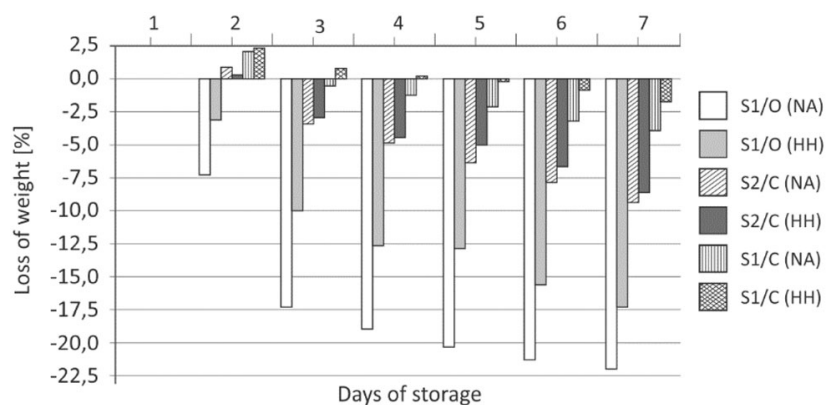

Fig. 3 Change in weight of S1 and S2 samples, stored in (NA)-(HH) conditions, in an open and closed container

than value of change in weight of S1/C sample (nut with the husk). Analysis of the obtained data lead to a conclusion that the husk is an effective protection against ambient conditions. The obtained data also show that husk as a 'packaging' makes the water release process about 2.5 times slower.

Complex assessment of change in weight of stored hazelnuts should cover influence of ambient conditions. Markuszewski and Kopytkowski (2015), suggested that modified storage conditions (i.e. $3 \% \mathrm{O}_{2} ; 3 \% \mathrm{CO}_{2}, 85-95 \%$ humidity) may significantly influence hazelnuts quality. $\mathrm{He}$ stated that low oxygen concentration and carbon dioxide, present during nut storage, effectively inhibited hazelnuts respiration, and simultaneously reduced development of fungal While analysing influence of ambient conditions on the process of water release it was observed that the greatest differences occur for samples stored in open containers. Closing sample in the container significantly reduces difference of weight change in (NA) conditions, (Table 3).

During tests, it was concluded that both in case of hazelnuts stored in $(\mathrm{HH})$ environment, and hazelnuts stored in closed containers, the smallest amount of weight is lost. For hazelnuts with husks, closing of the sample, reduces release of water for (NA) conditions for more than 5 times (Table 3).

Prior the test, initial values of water content in the kernel and in the husk were determined. The said values were determined for a selected husks sample and ground kernel sample. Water content of the husk was $22.01 \%$. In case of the kernel, the obtained value was $34.05 \%$. The values are comparable to results obtained by Markuszewski and Kopytkowski (2015), for Catalan hazelnut (34.6\% water content), and for Hall's Giant (34.5\% water content), stored for 3 months in $85-95 \%$ humidity, and temperature of ca. $1{ }^{\circ} \mathrm{C}$ at normal atmosphere.

Next water content in husk and kernels was determined after 9-day long simulated shelf-life period. The test concerned hazelnuts stored in (NA) and (HH) conditions. The kernels were separated from the husks, then, in accordance with the requirements of EU Commission Regulations, they were crumbled, and finally divided into 4 samples, each of them representing particular combination with regard to packaging type and environment. Each sample was dried until constant weight value for $103{ }^{\circ} \mathrm{C}$ temperature got obtained. Obtained water content for samples was as follows: packaging type (OPEN), ambient conditions (NA): 4,02\%, packaging type (OPEN), ambient conditions (HH): 7,07\%, packaging type (CLOSED), ambient
Table 2 Loss of weight of S1and S2 samples, expressed in percent, and with regard to ambient conditions and size of crumble level

\begin{tabular}{lllllll}
\hline $\begin{array}{l}\text { Sample name } \\
\text { Ambient conditions }\end{array}$ & S1/O & S1/O & S2/C & $\begin{array}{l}\text { S2/C } \\
\text { HH }\end{array}$ & $\begin{array}{l}\text { S1/C } \\
\text { NA }\end{array}$ & $\begin{array}{l}\text { S1/C } \\
\text { HH }\end{array}$ \\
\hline 1 & 0 & 0 & 0 & 0 & 0 & 0 \\
2 & -7.21 & -3.07 & 0.74 & 0.13 & 2.00 & 2.22 \\
3 & -17.34 & -9.99 & -3.47 & -2.93 & -0.49 & 0.80 \\
4 & -18.95 & -12.59 & -4.84 & -4.42 & -1.28 & 0.10 \\
5 & -20.33 & -12.88 & -6.36 & -4.98 & -2.15 & -0.14 \\
5 & -21.30 & -15.67 & -7.76 & -6.68 & -3.21 & -0.96 \\
7 & -21.97 & -17.32 & -9.41 & -8.63 & -3.91 & -1.73 \\
\hline
\end{tabular}


Table 3 Change in weight of S1 and S2 samples, stored in (NA) conditions, expressed in percent

\begin{tabular}{|c|c|c|c|}
\hline & $\begin{array}{l}\text { S1/O Sample Nuts } \\
\text { with husks Open } \\
\text { packaging }\end{array}$ & $\begin{array}{l}\text { S1/C Sample Nuts } \\
\text { with husks Closed } \\
\text { packaging }\end{array}$ & $\begin{array}{l}\text { S2/C Sample Nuts } \\
\text { without husks Closed } \\
\text { packaging }\end{array}$ \\
\hline Total loss of weight $\Delta \mathrm{m}$, (NA) conditions & $21.97 \%$ & $3.91 \%$ & $9.4 \%$ \\
\hline $\begin{array}{l}\text { Difference of samples' weight change with regard to packaging } \\
\text { type, the same ambient conditions } \Delta \mathrm{m}_{(\mathrm{NA})}(\mathrm{S} 1 / \mathrm{O}-\mathrm{S} 1 / \mathrm{C})\end{array}$ & & $18.6 \%$ & \\
\hline $\begin{array}{l}\text { Difference of samples' weight change, husks presence/absence } \\
\text { referred to, constant ambient conditions and the same packaging } \\
\text { method applied. } \Delta \mathrm{m}_{(\mathrm{NA})}(\mathrm{S} 2 / \mathrm{C}-\mathrm{S} 1 / \mathrm{C})\end{array}$ & & & $5.49 \%$ \\
\hline
\end{tabular}

conditions (NA): 21,70\%, packaging type (CLOSED), ambient conditions (HH): 21,32\%.

The analysis led to a conclusion that storing hazelnuts in an open container in an environment of higher humidity results with twice shorter period of time when it comes to release of water from the hazelnuts kernel. For samples stored in closed packaging, the water content values were comparable regardless of the ambient conditions. Presented data confirm that the best method for storing the hazelnuts is hermetically closed packaging. On the basis of the results it was concluded that previously obtained changes in weight of S1/C sample, stored in (NA) conditions, concerned mostly the husk, kernel's water content value did not decrease significantly. This in turn shows that the husk is a natural hazelnut packaging slowing down process of release of water from the kernel, simultaneously protecting the hazelnut against unfavourable oxidation processes (San Martin et al. 2001).

The water content for the same samples was also determined using the infrared method (MA.R moisture analyzer). Through the Q-Dixon test, it was checked whether there were any results with excessive error in the data set. The following results were obtained:

$R=x_{n}-x_{1}=0,665($ series 1$) ; 0,825($ series 2$)$

$Q_{1}=\frac{x_{2}-x_{1}}{R}=0,008($ series 1$) ; 0,006($ series 2$)$

$Q_{n}=\frac{x_{n}-x_{n-1}}{R}=0,063($ series 1$) ; 0,147($ series 2$)$

Critical value, $\mathrm{Q}_{\mathrm{kr}}$, for significance level of $0.05(95 \%)$ and 10 degrees of freedom, was 0.412 . None of the calculated $\mathrm{Q}_{1}, \mathrm{Q}_{\mathrm{n}}$ values was greater than $\mathrm{Q}_{\mathrm{kr}}$ value, this means that within the set of analysed data there were no results affected by gross errors.

Average value of water content determination for tested hazelnuts sample was $5.94 \%$, where the standard deviation was $0.26 \%$. The water content obtained by the moisture analyzer method is slightly higher than the value obtained by Biernat et al. (2014), 5.02\%, who tested nuts purchased on the market. Distribution of deviations of successive measurements with regard to the average value is presented in Fig. 4.

On the basis of the results it was stated that maximum difference regarding water content in the series of measurements was $0.83 \%$. According to the authors, in order to obtain less dispersed indications, further optimisation of drying parameters is required, i.e. heat source of a different radiation wavelength must be selected. As Markuszewski and Kopytkowski (2015) states, smaller dispersion of indications can also be obtained by modifying the way hazelnuts are stored, more precisely by controlling the atmosphere. The above described results confirm that the suggested method of determination of water content is faster than the method required by EC regulations (2002). The analysis took about $5 \mathrm{~min}$, however it was noted that its duration was conditioned by sample mass. Increasing dried sample weight to $15 \mathrm{~g}$, resulted with longer drying time, in this case drying took more than $20 \mathrm{~min}$. The tests allowed to observe that applying increased drying temperature, $120{ }^{\circ} \mathrm{C}$ and higher, results with change in dried sample colour. This is caused by surface burning of the sample (Bradley 2010), which in turn brings result that is much higher than the expected value.

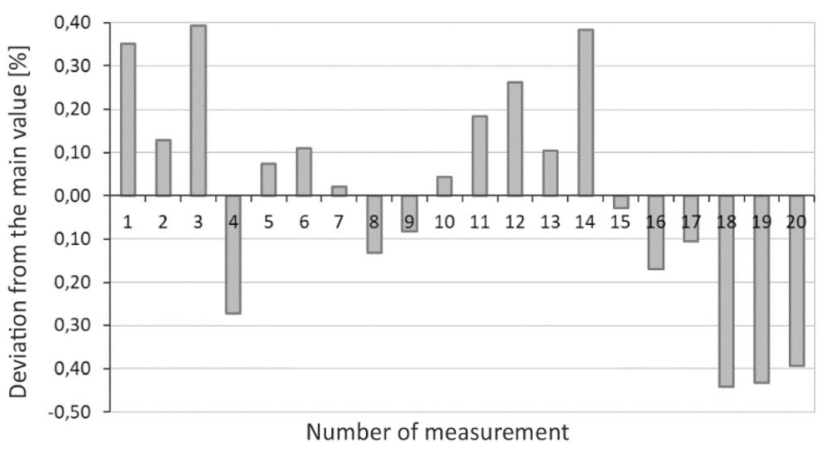

Fig. 4 Deviations of water content values determined for kernels in relation to the average value 


\section{Conclusions}

It has been confirmed that hazelnuts lose mass regardless of the storage environment. The best stability of hazelnut weight over time is obtained when the relative humidity of hazelnut storage is around $80 \%$. This is one of the guidelines that can be used when designing hazelnut logistics and storage systems. However, attention must be paid to the potential for mold and mitotoxin contamination, especially when the kernel is not protected by the shell. This problem is practically non-existent when the relative humidity in the storage warehouse is around 50\%. Unfortunately, in this case a greater loss of grain weight over time must be taken into account, which is disadvantageous for economic reasons. One solution to this problem is to use packaging with controlled diffusion of the material, e.g. type Xtend ${ }^{\circledR}$. Regardless of the applied storage methods, the water content of nuts should be verified periodically to maintain high product quality and reduce the risk of losses. In this study it was confirmed that the moisture analyser can be effectively applied in the process of water content testing. The mobility and ergonomics of this device indicates the possibility of adaptation in any laboratory, but also directly in the technological process. Determination of water content using a moisture analyser compared to standard methods saves time. However, an important issue from the metrological point of view is the validation of the method and the device. Such a procedure was carried out in the above work, so that it was possible to propose reproducible, rapid methodologies for obtaining true error-free moisture content in nuts. One of the advantages of the weighing dryer is its simplicity of use and low cost (about 1000 Euro) which makes it accessible to a wide range of customers.

The work also proved that hazelnut shell is an excellent natural protection of the nut kernel, as it more than doubles the loss of its mass. This is important information for producers determining the shelf life of hazelnuts.

Author contributions Conceptualization: [MK, SJ], Methodology: [SJ, MK], Formal analysis and investigation: [SJ, PM], Writingoriginal draft preparation: [SJ, MK]; Writing-review and editing: [SJ], Supervision: $[\mathrm{MK}]$.

Funding The authors did not receive support from any organization for the submitted work.

\section{Declarations}

Conflict of interest The authors declare that they have no conflict of interest.

Human and animals rights No research involving Human Participants and/or Animals.
Open Access This article is licensed under a Creative Commons Attribution 4.0 International License, which permits use, sharing, adaptation, distribution and reproduction in any medium or format, as long as you give appropriate credit to the original author(s) and the source, provide a link to the Creative Commons licence, and indicate if changes were made. The images or other third party material in this article are included in the article's Creative Commons licence, unless indicated otherwise in a credit line to the material. If material is not included in the article's Creative Commons licence and your intended use is not permitted by statutory regulation or exceeds the permitted use, you will need to obtain permission directly from the copyright holder. To view a copy of this licence, visit http://creativecommons. org/licenses/by/4.0/.

\section{References}

Adegbola YP, Ahoyo Adjovi NR, Adekambi SA, Zossou R, Sonehekpon ES, Assogba Komlan F, Djossa E (2019) Consumer preferences for fresh tomatoes in Benin using a conjoint analysis. J Int Food Agribus Mark 31(1):1-21. https://doi.org/10.1080/ 08974438.2018.1469448

Biernat J, Drzewicka M, Łoźna K, Hyla J, Brankowska M, Grajeta H (2014) Skład kwasów tłuszczowych orzechów i nasion dostępnych aktualnie w handlu w kontekście prozdrowotnych zaleceń żywieniowych. Bromatol i Chem Toksykologiczna, XLVII 2, 121-129. YADDA: bwmeta1.element.agroe4e49364-19f7-4a97-8759-177465a9fb58

Bradley R, L Jr (2010) Moisture and total solids analysis In: Suzanne Nielsen S (Ed), Food Analysis. Fourth Edition. (pp 85-104). West Lafayette, Springer US. https://doi.org/10.1007/978-14419-1478-1_6

Campbell BC, Molyneux RJ, Schatzki TF (2003) Current research on reducing pre- and post-harvest af-latoxin contamination of US almond, pistachio and walnut. Toxin Rev 22:225-266. https:// doi.org/10.1081/TXR-120024093

Chlebowska-Śmigiel A, Gniewosz M (2009) Wpływ jadalnej powłoki pullulanowej na ograniczenie zmian sensorycznych i fizykochemicznych zachodzacych w orzechach laskowych podczas ich przechowywania. Bromatol i Chem Toksykol XLII 3:420-425

Ciemniewska H, Ratusz K (2012) Characteristics of hazelnuts from three hazel cultivars grown in Poland. Rośliny Oleiste 33(2):273-283

Commission Regulation (EC) No 1284/2002. 2002. Laying down the marketing standard for hazelnuts in shell.

Derewiaka D, Paliwoda M, Zaręba D (2014) Wpływ przechowywania na profil związków lotnych wybranych gatunków orzechów. Nauka Przyroda Technol 8(4):51-66

Ercisli S, Ozturk I, Kara M, Kalkan F, Seker H, Duyar O, Erturk Y (2011) Physical properties of hazelnuts. Int Agrophy 25(2):115-121

Ghirardello D, Contessa C, Valentini N, Zeppa G, Roll L, Gerbi V, Botta R (2013) Effect of storage conditions on chemical and physical characteristics of hazelnut (Corylus avellana L.). Postharvest Biol Technol 81:37-43. https://doi.org/10.1016/j. postharvbio.2013.02.014

Guiné RP, Almeida CF, Correia PM (2015) Influence of packaging and storage on some properties of hazelnuts. J Food Meas Charact 9(1):11-19. https://doi.org/10.1007/s11694-014-9206-3

Kaya A, Aydin O, Akgun M (2011) Drying kinetics and moisture transfer parameters of hazelnut. J Food Process Preserv 35(5):714-721. https://doi.org/10.1111/j.1745-4549.2011. 00522. $\mathrm{x}$ 
Markuszewski B, Kopytowski J (2015) Effects of storage conditions on the quality of unripe hazelnuts in the husk. J Hortic Res 23(2):59-67. https://doi.org/10.2478/johr-2015-0016

Moscetti R, Frangipane MT, Monarca D, Cecchini M, Massantini R (2012) Maintaining the quality of unripe, fresh hazelnuts through storage under modified atmospheres. Postharvest Biol Technol 65:33-38. https://doi.org/10.1016/j.postharvbio.2011.10.009

Navarro S (2006) Modified atmospheres for the control of stored product insects and mites. In: International AACC (ed) Insect management for food storage and processing. J.W. Heaps, St. Paul USA, pp 105-146

Papetti P, Carelli A (2013) Composition and sensory analysis for quality evaluation of a typical Italian cheese: influence of ripening period. Czech J Food Sci 31(5):438-444. https://doi. org/10.17221/447/2012-CJFS

San Martin MB, Fernández-García T, Romero A, Lopez A (2001) Effect of modified atmosphere storage on hazelnuts quality.
J Food Process Preserv 25(5):309-321. https://doi.org/10.1111/j. 1745-4549.2001.tb00463.x

Savage GP, McNeil DL, Dutta PC (1997) Lipid composition and oxidative stability of oils in hazelnuts (Corylus avellana L.) grown in New Zealand. J Am Oil Chem Soc 74(6):755-759. https://doi.org/10.1007/s11746-997-0214-x

Tavakoli J, Sedaghat N, Mousavi Khaneghah A (2019) Effects of packaging and storage conditions on Iranian wild pistachio kernels and assessment of oxidative stability of edible extracted oil. J Food Process Preserv 43(4):e13911. https://doi.org/10. 1111/jfpp.13911

Publisher's Note Springer Nature remains neutral with regard to jurisdictional claims in published maps and institutional affiliations. 